\title{
Impacts of recirculation event on aerosol dispersion and rainfall patterns in parts of Nigeria
}

\author{
Emetere* M.E. \\ Physics Department, Covenant University, P.M.B. 1023, Ota-Ogun State, Nigeria \\ Received: 08/10/2016, Accepted: 10/01/2017, Available online: 06/10/2017 \\ *to whom all correspondence should be addressed: emetere@yahoo.com
}

\section{Abstract}

The peculiarity of the lower atmosphere of south west region of Nigeria was explored using theoretical and experimental approach. In the theoretical approach, the reconstruction of $1 D$ model as an extraction from the $3 D$ aerosol dispersion model was used to examine the physics of the recirculation theory. The experimental approach which consists of obtaining dataset from ground instruments was used to provide on-site guide for developing the new recirculation theories. The data set was obtained from the Davis weather station, Nigeria Meteorological agency and Multi-angle Imaging Spectroradiometer (MISR). We looked at the main drivers of recirculation and propounded that recirculation is a complex process which triggers a reordering of the mixing layer- a key factor for initiating the type of rainfall in this region.

Keywords: Aerosol, dispersion model, rainfall, recirculation theory, wind, climate

\section{Introduction}

The role of aerosols in understanding the climatic system is enormous because it controls verse processes in the atmosphere like atmospheric circulation (Alfano et al., 2015), rainfall pattern (Rotstayn and Lohman, 2002) cloud formation (Allen and Sherwood, 2010). Its direct and indirect influence on the global climate can be very complicating when understudying the comparative role of aerosols to global energy balance (Mao et al., 2014). Atmospheric aerosols have been reported to form heterogeneous or homogenous layers in the atmosphere (Emetere et al., 2015a). This is possible because the layer formed depends on its size, chemical and physical properties and initial source of dispersion. Aerosol Optical Thickness (AOT) of magnitude - less than 0.1 signifies a crystal clear sky of maximum visibility. Also, AOT of magnitude of 1 indicates very hazy sky of poor visibility (Alfano et al., 2015). There are newer measuring instruments for estimating AOT of vertical profiles of aerosol plumes and clouds. This instrument includes the Cloud Aerosol Lidar and Infrared Pathfinder Satellite Observer (CALIPSO), Multi-angle Imaging Spectroradiometer (MISR) and the Moderate Resolution Imaging
Spectro-radiomer (MODIS). The Aerosols Robotic Network (AERONET) comprise of more than 200 calibrated sun photometers for measuring aerosol optical depth around the world (Voiland, 2010). However, these instruments do not run independently. Models are propounded to maximize the functionality and accuracy of the measuring instruments. Unfortunately, these model needs improvement in several areas e.g. adequate estimation of aerosol dispersion and deposition, rates of new particle formation and their dependence on controlling variables e.g. growth and aging. The aerosols dispersion and deposition technique requires a systemic evaluation of aerosols not only at ground level but also in the planetary boundary layer $(\mathrm{PBL})$ to determine the aerosol transport mechanism-in relation to weather formation at the PBL (Voiland, 2010; Emetere et al., 2015b). The planetary boundary layer contains a large variety of aerosols from anthropogenic and natural sources (Andreas, 1999). The planetary boundary layer (PBL) comprises of sub-layers e.g. mixed layer, surface layer, stable layer and residual layer. The surface layer is closest to the earth i.e. 10 percent of the height of the PBL. Turbulent stresses are relatively constant. The mixed layer or convective layer are directly above the surface layer and are characterized by convective motion and significant mixing of air. It makes up the entire layer of the PBL above the surface layer during day and reduces drastically during the night. The stable layer is located above the mixed layer. It is the entry point where air from above the PBL entrains into the mixed layer. This stable layer restricts turbulence, prevents frictional influences from reaching above the PBL and prevents the continued upward motion of thermals. The residual layer is mainly residuals of the mixed layer and is not influenced by turbulent stresses. The PBL are influenced by environment forces like differential heating, energy budgets, moisture, diurnal variations, buoyancy, shear, and roughness length. The PBL eliminates aerosols via natural mechanisms which operate either as wet deposition, dry deposition or chemical reactions. These processes can occur individually or simultaneously. Layering of the PBL is dependent on its temperature.

In this study, the examined site (see Figure 1) transverses the coastal region (in the south of Nigeria) to the sub-Sahel region (in the north of Nigeria). Dramatically, the wind 
transport mechanism initiates turbulent stress on the PBL. For example, during harmattan, the wind transports large quantities of dust particles from the Sahara Desert in the north to the south. Also, aerosols due to bush burning, automobile activities in the south increase the aerosols content over the study site (figure 1). During the nonharmattan, the West African Sub region is washed by the humid SW Monsoon winds from the Atlantic Ocean (Okpani, 2009).

The recirculation theory helps us to understand the anomalies in both the aerosols dispersion and deposition points of the atmospheric field settings. The mysteries of the recirculation zones in the mixing layer of the lower atmosphere are yet to be explained i.e. comparing the precirculation and post circulation. The turbulent boundary layers formed during recirculation are somewhat complex when explaining the minute changes that triggers continuous recirculation (Kim and Patel, 2000; Sadek et al., 2011). In this paper, the main objective is to examine a 3D dispersion model which was developed from the aerosols dispersion dynamics around a cement factory. We looked at the main drivers of recirculation and propounded that recirculation is a complex process which triggers a reordering of the mixing layer- a key factor for initiating the type of rainfall in this region.

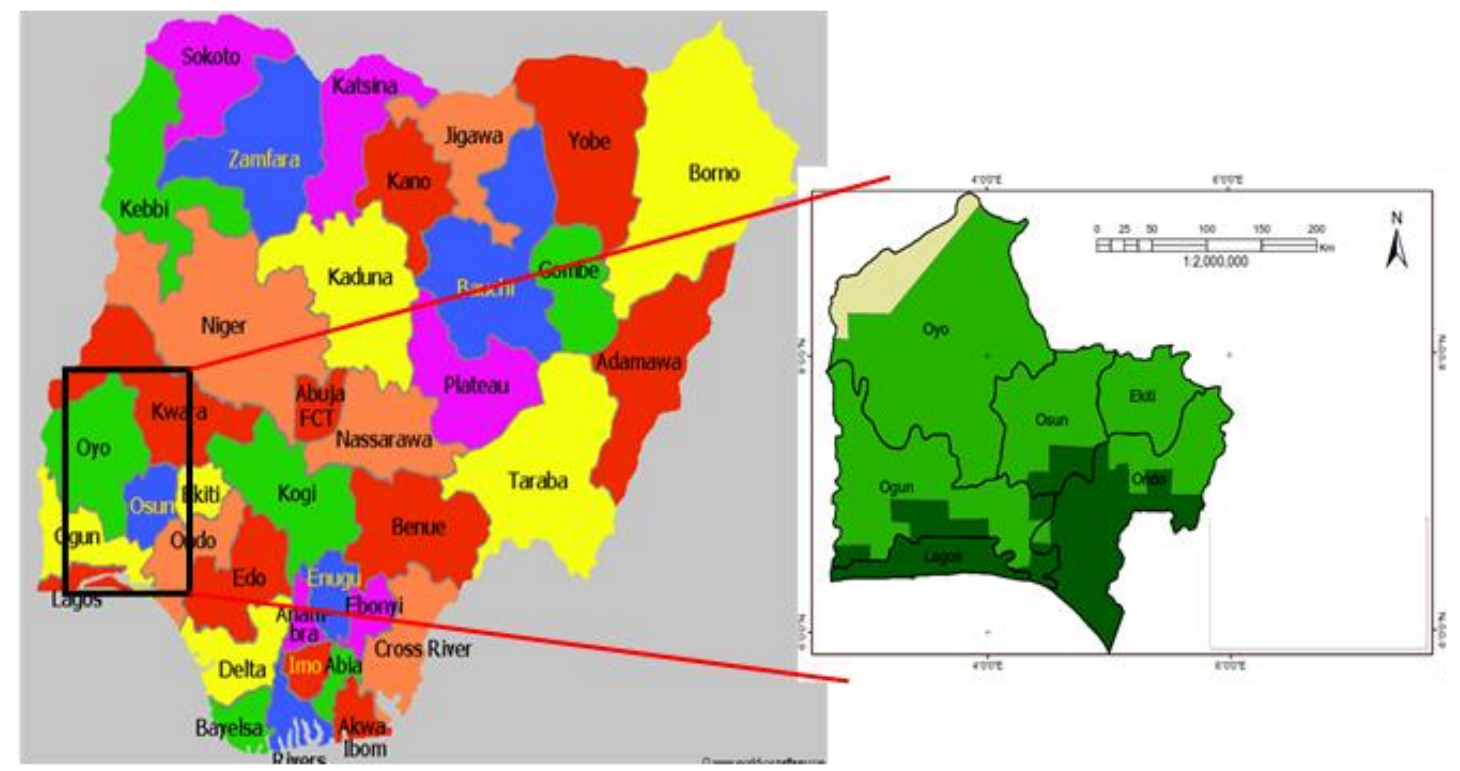

Figure 1. South West region of Nigeria

\section{Methodology}

The recirculation theory was reviewed via the use of ground measuring instrument located in the South West region of Nigeria. The Davis weather station used for this study was installed at Covenant University, Ota Nigeria. Ota is on $6.21^{\circ} \mathrm{N}$ and $3.21^{\circ} \mathrm{E}$. The weather station was used to obtain the wind properties i.e. peculiar to the region. The Meteorological data for rainfall was obtained from the Nigerian Meteorological Agency for five States in the southwest i.e. Osogbo-Osun, Ilorin-Kwara, Ibadan-Oyo, Abeokuta-Ogun, Ondo-Ondo and Ikeja-Lagos. The main objective of the theoretical approach is to derive recirculation equations from micro scale. The results from the micro-scale are then extended to the meso-scale. Recall the idea of the paper examines the effect of large scale recirculation on the rainfall patterns. The area of study is the south-west region of Nigeria. The satellite imagery (MISR) for the aerosol optical depth of the locations were examined. The theoretical approach to these studies can be obtained from the aerosol dispersion model (Emetere et al., 2015c; Emetere et al., 2015d). The $3 \mathrm{D}$ model for consideration is given as:

$$
\begin{aligned}
& \frac{\partial C}{\partial t}+V_{x} \frac{\partial C}{\partial x}-V_{z} \frac{\partial C}{\partial z}-V_{y} \frac{\partial C}{\partial y}=\frac{\partial}{\partial z}\left(K_{z} \frac{\partial C}{\partial z}\right)+\frac{\partial}{\partial y}\left(K_{y} \frac{\partial C}{\partial y}\right)+\frac{\partial}{\partial z}\left(K_{z 2} \frac{\partial C}{\partial z}\right)+\frac{\partial}{\partial y}\left(K_{y 2} \frac{\partial C}{\partial y}\right)-P+S \\
& -V_{z} \frac{\partial C}{\partial z}=-\frac{\partial}{\partial z}\left(K_{z} \frac{\partial C}{\partial z}\right)+\frac{\partial}{\partial y}\left(K_{y} \frac{\partial C}{\partial y}\right) \\
& V_{x} \frac{\partial C}{\partial x}=\frac{\partial}{\partial y}\left(K_{y 2} \frac{\partial C}{\partial y}\right)-\frac{\partial}{\partial z}\left(K_{z 2} \frac{\partial C}{\partial z}\right)
\end{aligned}
$$

Here, $C(x, y, z)$ is the pollutants diffusion mean concentration at a point $(x, y, z)\left[\mathrm{kg} / \mathrm{m}^{3}\right], K_{y}, K_{x}$ is the eddy diffusivities in the direction of the $y$ - and $z$ - axes $\left[\mathrm{m}^{2} / \mathrm{s}\right]$. The reconstruction of the 3D model is achieved via Figures 2-3 
In Figure 2, the recirculation favours the upward motion into the free troposphere. In Figure 3, the recirculation influences a downward motion within the frictional boundary of the lower atmosphere. In figure 4, the recirculation is a sustained recirculation that impacts upon the upward and downward motion. This kind of circulation is common in a large scale wind dynamic as shown in Figure 5.

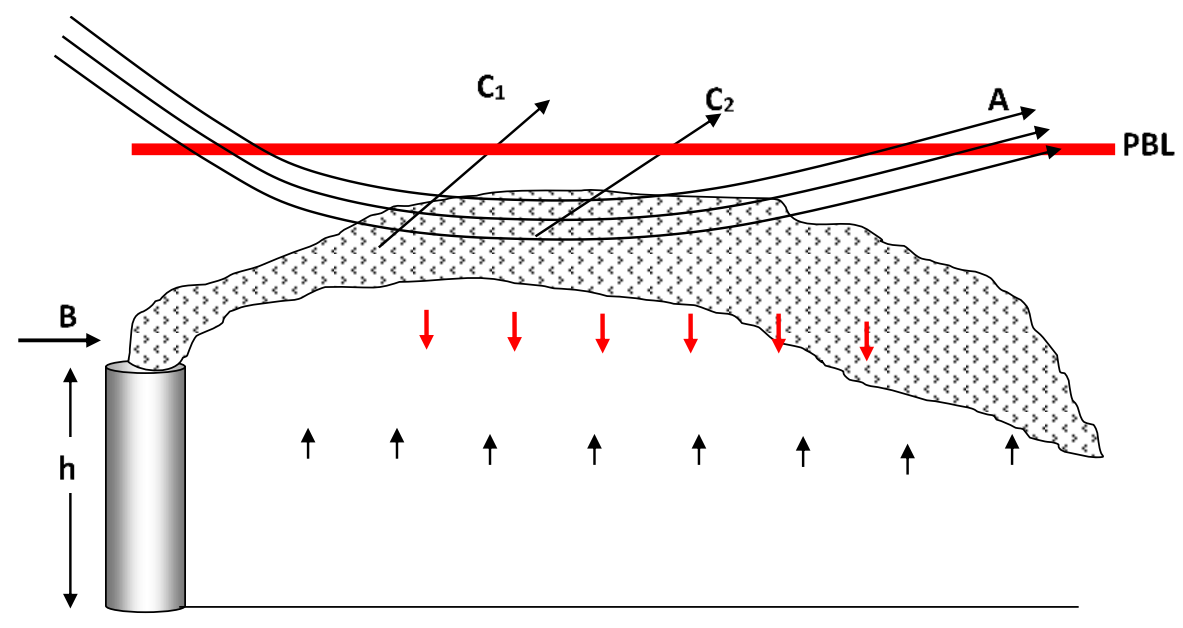

Figure 2. Type 1 recirculation dispersion pattern from cement Factory

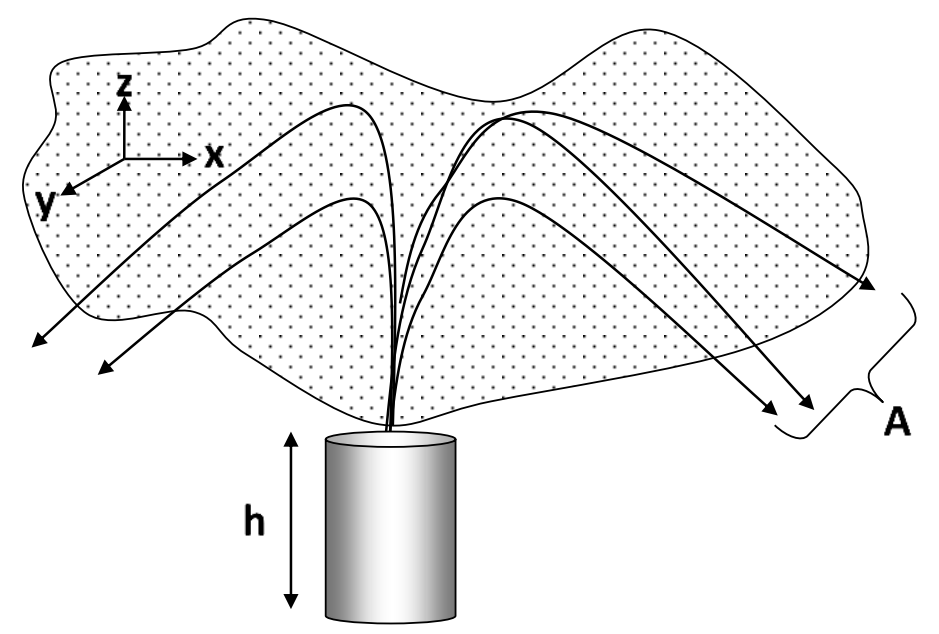

Figure 3. Type 2 recirculation dispersion pattern from cement Factory

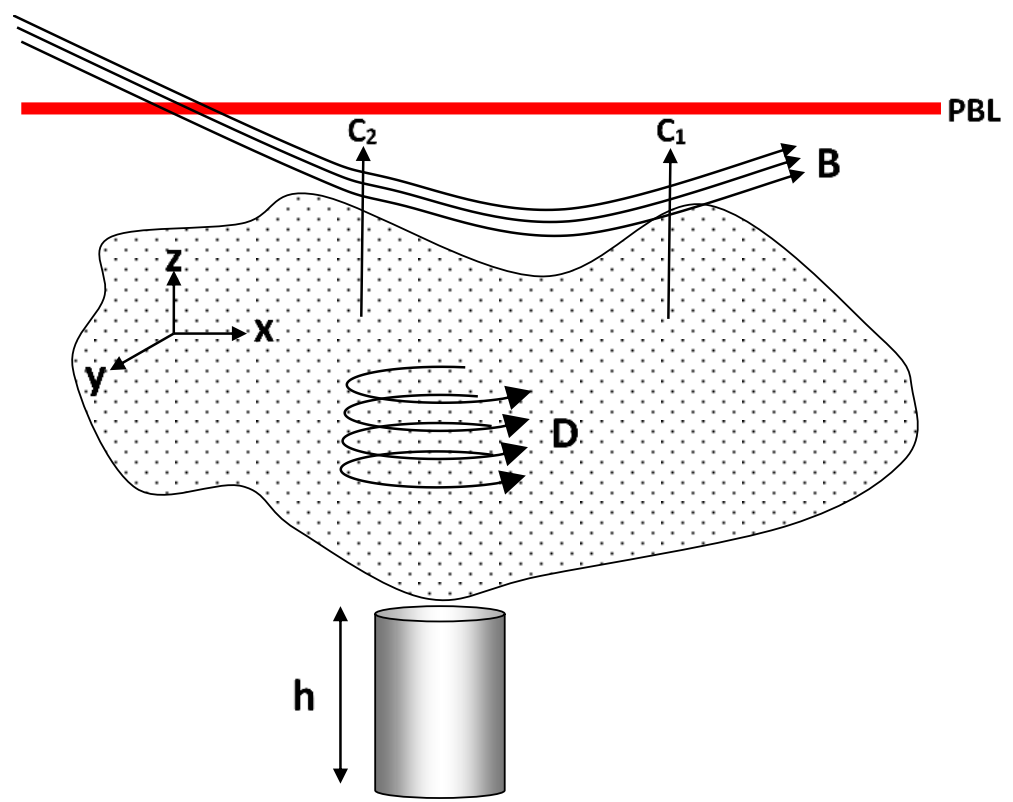

Figure 4. Type 3 recirculation dispersion pattern from cement Factory 


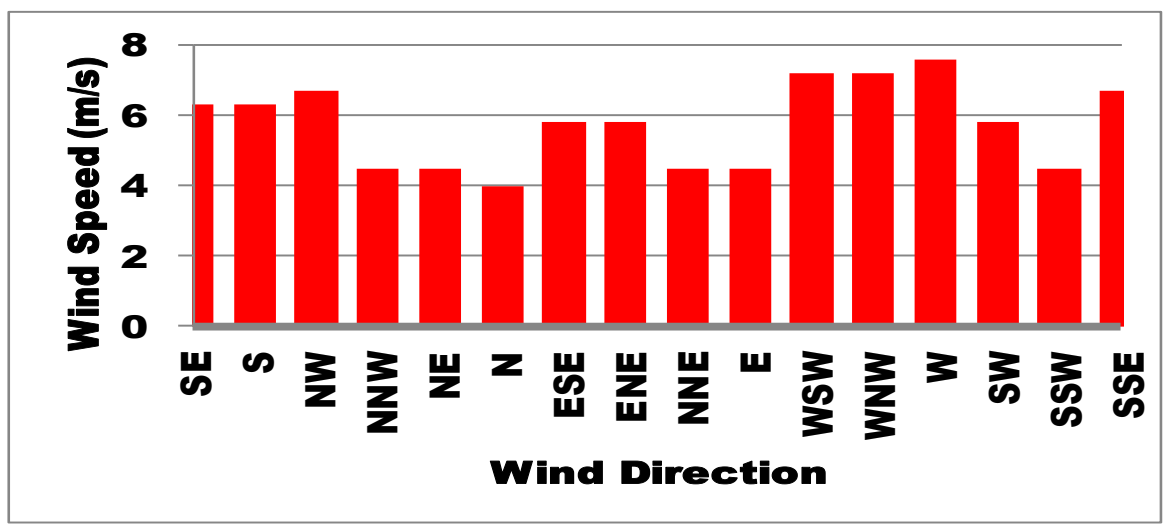

Figure 5. Magnitude of wind speed within different directions

In this paper, we are more interested in type 3 which gives a prediction for a large scale recirculation event and its effect on the rainfall patterns for thirteen years. Type 3 is the most prevalent during recirculation in the in or below

$$
\frac{\partial C}{\partial t}+V_{x} \frac{\partial C}{\partial x}-V_{z} \frac{\partial C}{\partial z}-V_{y} \frac{\partial C}{\partial y}=\frac{\partial}{\partial z}\left(K_{z} \frac{\partial C}{\partial z}\right)+\frac{\partial}{\partial y}\left(K_{y} \frac{\partial C}{\partial y}\right)+\frac{\partial}{\partial z}\left(K_{z 2} \frac{\partial C}{\partial z}\right)+\frac{\partial}{\partial y}\left(K_{y 2} \frac{\partial C}{\partial y}\right)-B+D
$$

Here D represents the transport equations for recirculation; $B$ is the pressure gradient force.

$$
D=\frac{\partial\left(V_{x} \epsilon\right)}{\partial x}=\frac{\partial}{\partial x}\left(\frac{V_{t}}{\sigma_{\epsilon}} \frac{\partial \epsilon}{\partial x}\right)-k
$$

$$
B=d P . d A
$$

Here $V_{x}$ is the mean velocity in $\mathrm{x}$ direction, $\mathrm{P}$ is the pressure, $A$ is the surface area, $V_{t}$ is the kinematic viscosity, $\epsilon$ is the turbulence kinetic energy, $\mathrm{k}$ is the dissipation rate, $\sigma_{\epsilon}$ turbulent diffusivity coefficient.

$$
\frac{\partial C}{\partial t}+V_{x} \frac{\partial C}{\partial x}=V_{x} \frac{\partial C}{\partial x}+\frac{\partial}{\partial x}\left(\frac{V_{t}}{\sigma_{\epsilon}} \frac{\partial \epsilon}{\partial x}\right)-k
$$

Equation 7 has important implications for precipitation formation via the recirculation region. The recirculation region initiates the nucleation scavenging which grows the precipitation size. The ability of aerosol particles to act as a cloud condensation nuclei (CCN) depends on its size (Westervelt et al., 2014). The solution of equation (7) is given as

$$
\epsilon=\frac{\sigma_{\epsilon}}{V_{t}}\left(-V_{x}(k t+C-x)-P A x\right)
$$

The solution i.e. equation (8) shows that the updraft term $x V_{x} \frac{\sigma_{\epsilon}}{v_{t}}$ was able to initiate the nucleation scavenging. Hence, large scale recirculation may influence precipitation over an area provided that other terms in equation (8) are quite low. This assumption was verified by the rainfall and aerosol optical depth over the research site.

\section{Results and discussion}

In this section we tried to verify how intense is the relationship between the aerosol content of an area and the rainfall pattern. The data duration is thirteen years. the tropopause. This event is more frequent for locations close to coastal belt (Lee et al., 2014). The mathematical representation of type 3 is given as
First we examine the wind speed data (figure $5 \& 6$ ) from the Davis weather station to determine the various expected possibilities in the recirculation zones.

The wind data set for January, 2013 was used to estimate the recirculation zone in 1D where $x=z$. January, 2013 was chosen because it had the highest volume of wind speed data within the year (Akinyemi et al., 2016). More specifically, the recirculation zone occurs more frequently along the SE, S, ESE, ENE, E, SSW and SSE as shown in figure 6. If we assume that all the negative terms in equation 8 are minute, then the turbulence kinetic energy which defines the sustenance of the recirculation zone can be written as

$$
\epsilon \approx \mathrm{x} \mathrm{V}_{\mathrm{x}} \frac{\sigma_{\epsilon}}{\mathrm{V}_{\mathrm{t}}}
$$

Where

$$
V_{x}(\theta)=\left\{\begin{array}{lc}
V \sin \theta & \text { if } 0<x<480, \quad 0<\theta<\mathrm{pi} / 16 \\
V \cos \theta & \text { if } 480 \leq x<960, \quad \text { pi } / 16<\theta<\text { pi } / 8 \\
V(\sin \theta+\cos \theta) & \text { if } 960 \leq x<1440, \quad \text { pi } / 8<\theta<\text { pi } / 4 \\
V \sin ^{2} \theta & \text { if } 1440 \leq x<1920, \quad \text { pi } / 4<\theta<\text { pi } / 2 \\
V \cos ^{2} \theta & \text { if } 1920 \leq x<2400, \quad \text { pi } / 2<\theta<\text { pi }
\end{array}\right.
$$

$\frac{\sigma_{\epsilon}}{V_{t}}=0.01$, and $V=7.8 \mathrm{~m} / \mathrm{s}$ i.e. the highest speed with an equivalently high frequency. Let $x$ be the altitude of the lower atmosphere where altitude $1440 \mathrm{~m}$ to $2400 \mathrm{~m}$ represents the free troposphere. The recirculation activity was theoretically represented in figure 7.

The 3D representation of the recirculation parameters illustrated in equation (9), where the maximum turbulence kinetic energy over the research area is about $261 \mathrm{~J} / \mathrm{Kg}$ and occurs between $1000 \mathrm{~m}$ to $1500 \mathrm{~m}$ altitude. The divergence of recirculation features as seen by the red dotted lines is evidence that the recirculation zones are unpredictably dynamic. Hence, it possesses a verse ability to influence 
rainfall over an area. In the context of this paper, we are more concerned with the influence of the recirculation of aerosols which is expected to initiate significant effect on the rainfall over an area.

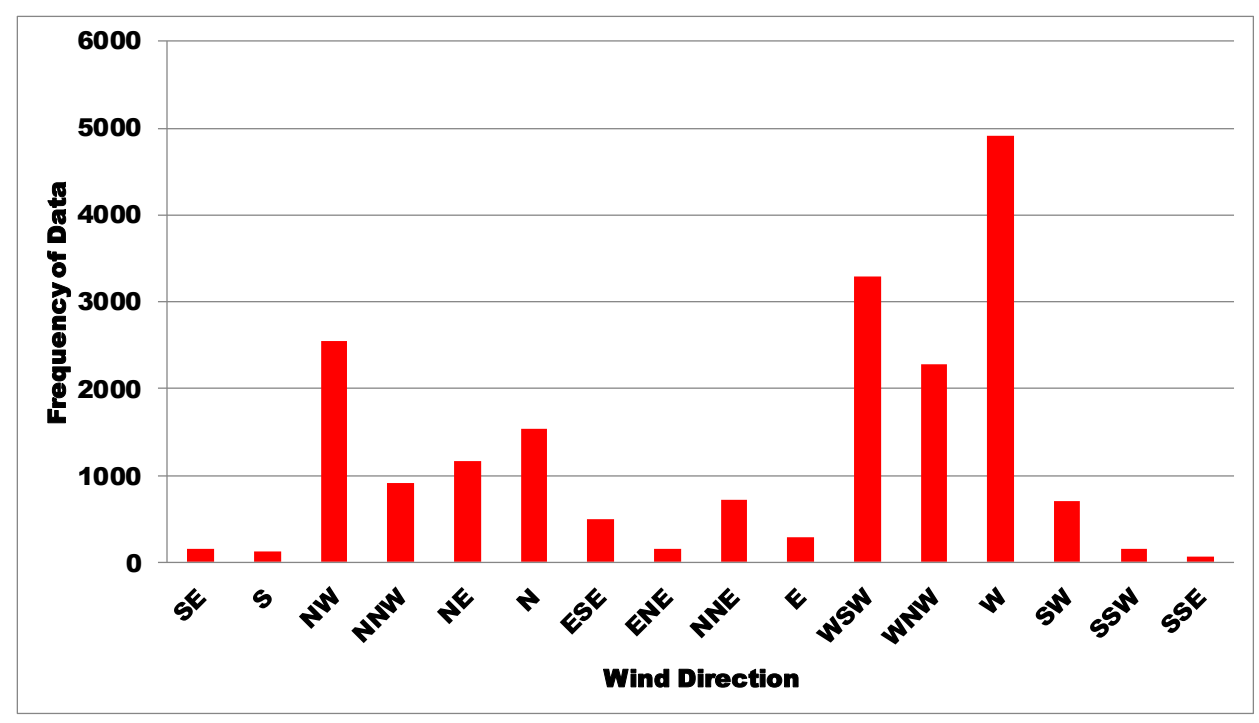

Figure 6. Frequency of wind directions

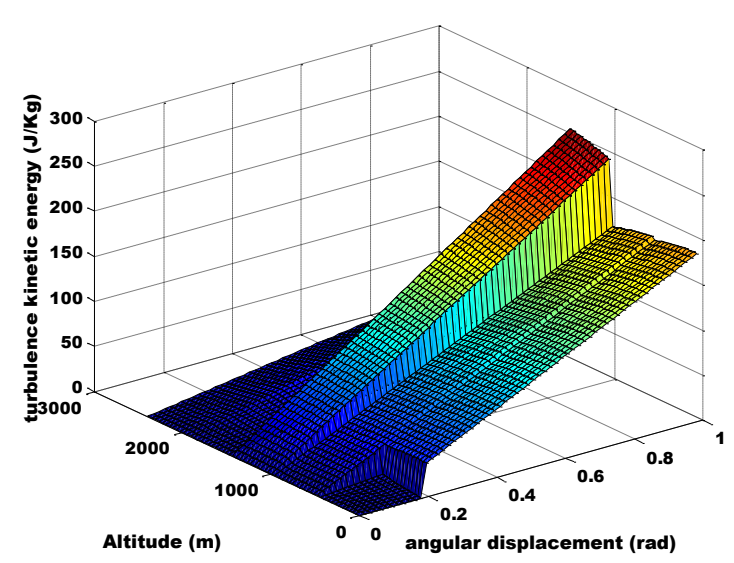

(a)

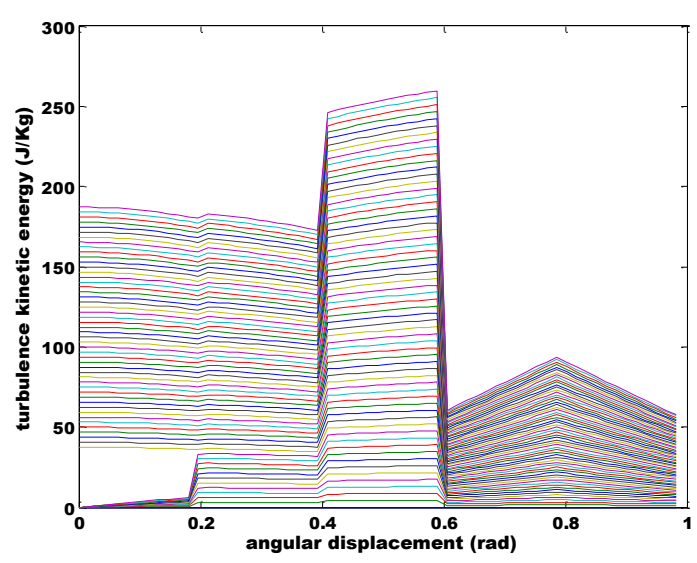

(b)

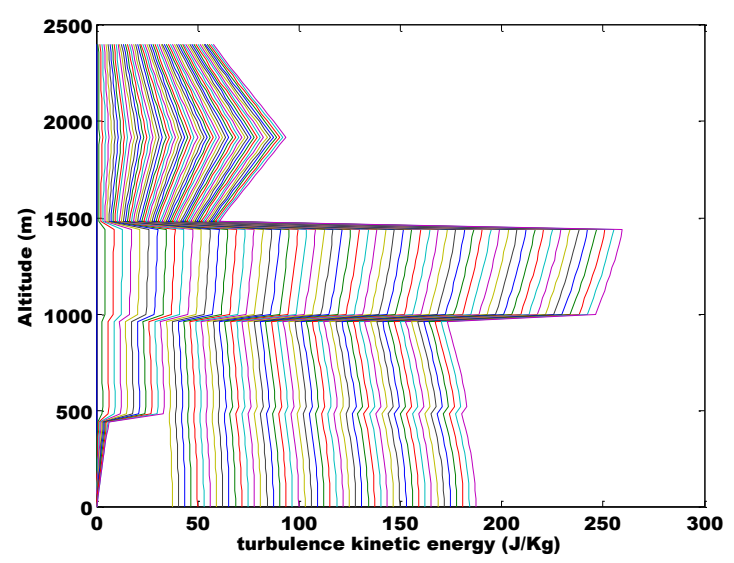

(c)

Figure 7. (a) 3D representation of recirculation parameter; (b) 2D representation of recirculation dynamics; (c) 2D representation of altitudinal influence on turbulence kinetic energy

We examined the rainfall pattern between the years 2000 to 2012 over the research locations because of its dismal occurrence in recent times. A comparative analysis between the rainfall pattern and the aerosol optical depth was carried to further explain the dynamic nature of the recirculation zones. The rainfall pattern of 2001 seems to be uniquely uniform with a clear evidence of uniform recirculation activity-throughout the six locations. Though other explanations can be given to the uniformity of the 2001 rainfall pattern, in this text, we tailored our argument towards the recirculation theory and how it influences rainfall (Figure 8). Aside the coastal location of Ikeja-Lagos where updrafts is expected to be high, the well defined aerosol optical depth over Lagos (figure 9a) contributes to 
the relatively high rainfall between the year 2000 and 2013. We propound that the region with influential recirculation activity possess a different rainfall pattern. Hence, llorin and Ikeja-Lagos had significant recirculation influence in 2000; Ondo and Osogbo in 2002; Osogbo, Ikeja-Lagos and Ondo in 2003; Ondo and Osogbo in 2004; Osogbo in 2005; Ikeja-Lagos and Osogbo in 2006; Ibadan in 2007 and 2009; Ikeja-Lagos in 2011; llorin in 2012.

In 2011, the recirculation in other location was relatively low; however, the recirculation impact in 2012 was high with a corresponding high rainfall throughout 2012. The aerosol optical depth in llorin is quite low compared to Lagos despite the influx of the dust aerosols from the Sahara via the north-east winds. This might have established our earlier guess that with adequate aerosols and recirculation, nucleation scavenging is triggered to collectively influence rainfall at the long run. The type of recirculation in Osogbo signifies a negative recirculation which favours the downdraft as expressed in figure 3 while the recirculation in Ikeja-Lagos signifies a positive recirculation which favours the updrafts as expressed in figure 4.

This study provides the hint into understanding the tropospheric anomaly noticed (Lee et al., 2014), it was proposed (via statistical analysis) that biomass burning aerosol (BBA) affects liquid clouds- leading to an increase in cloud droplet number concentrations and a decrease of droplet effective radii. In the long run, this process leads to geographical rearrangements of rainfall patterns (Sobel, 2010). The theory of recirculation as explain in this paper sheds more light on the possibility of rainfall suppression and promotion (Diem, 2013; lacobellis and Sommerville, 2006). The recirculation activity can influence the normal deceleration (in form of normalization, accelerating or decreasing) of auto-conversion processes in the lower atmosphere Weber and Quaas, 2012.
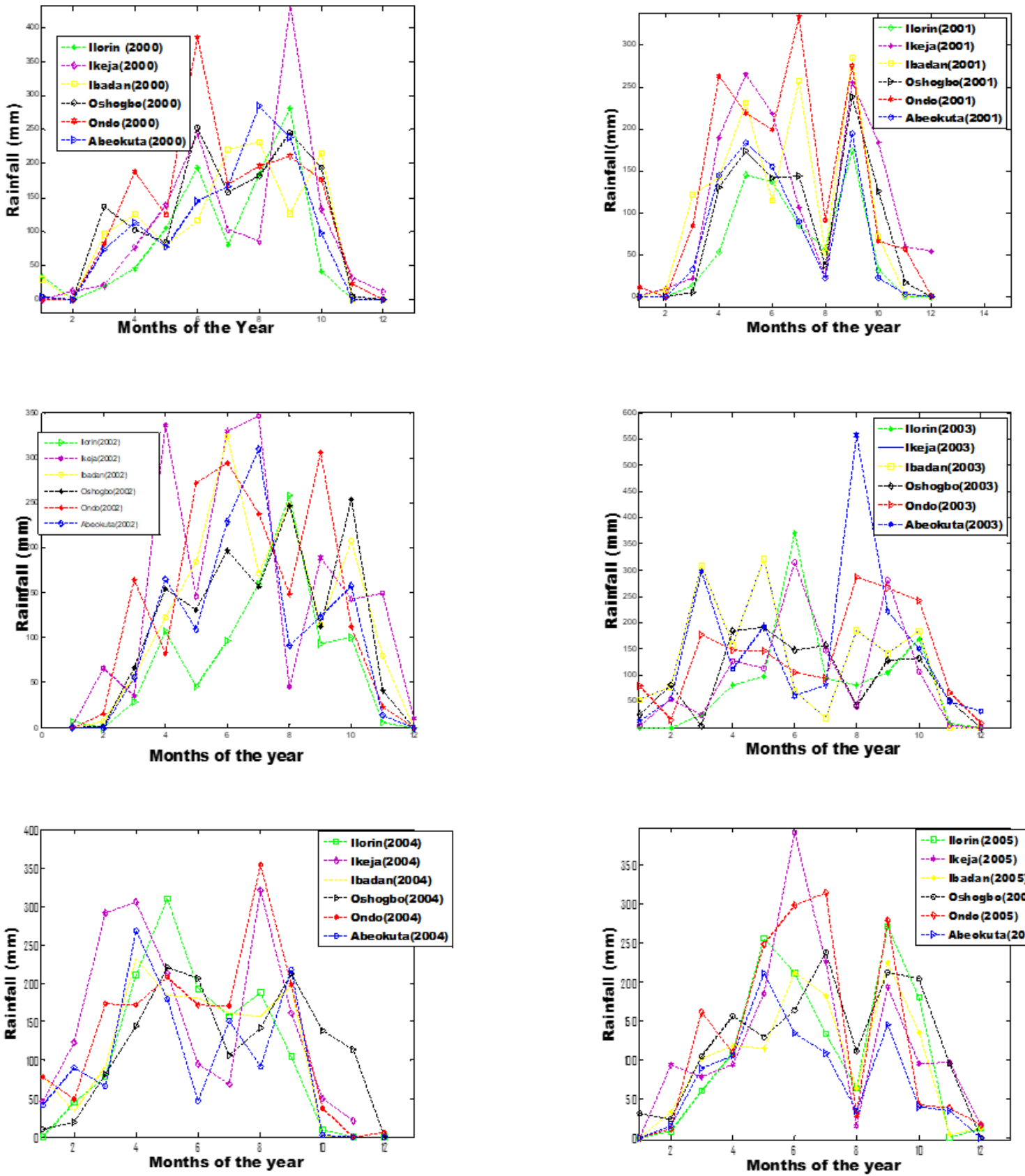

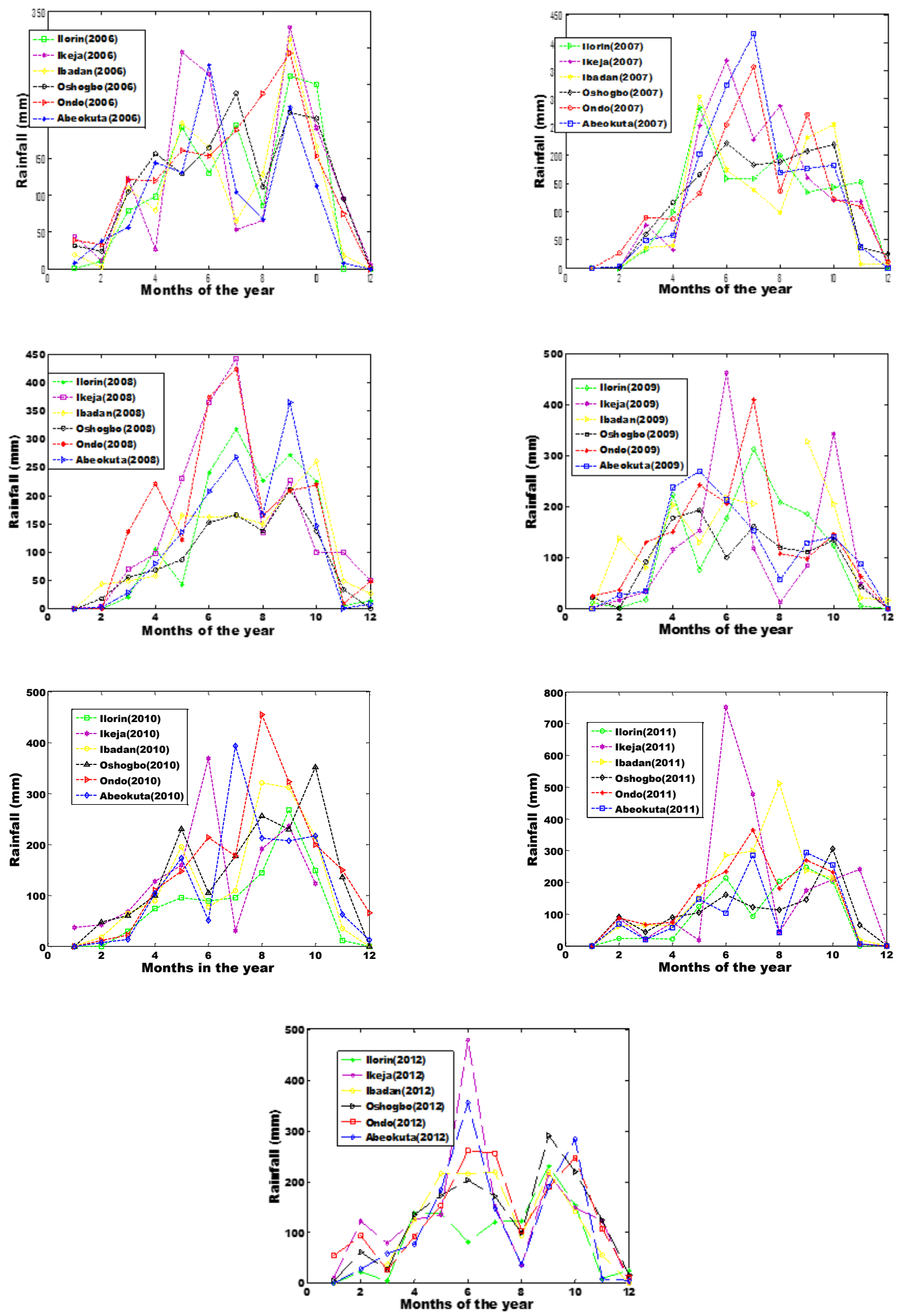

Figure 8. Rainfall pattern within the years 2000 to 2012 


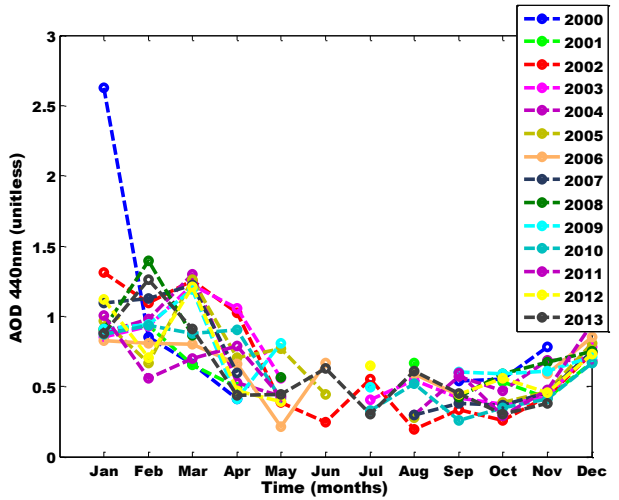

(a)

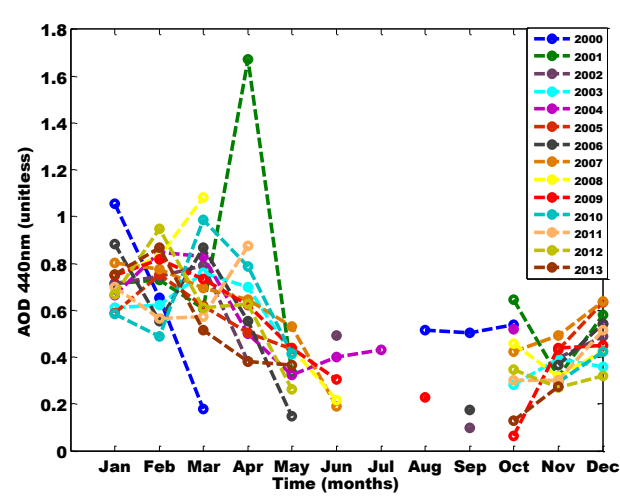

(b)

Figure 9. (a): AOD pattern within the years 2000 to 2012 for Lagos;

(b) : AOD pattern within the years 2000 to 2012 for Ilorin

The recirculation activity in the lower atmosphere controls the magnitude of increase in cloud condensation nuclei and by extension, the available potential energy. Figure 7c affirms the auto energy conversion from turbulence kinetic energy to available potential energy. Hence, the high turbulence kinetic energy between 1000m and 1500m affirms the aerosol effect on warm precipitation formation (Frank et al., 2003). It is therefore scientifically sensible to propose that the recirculation activity further complicates aerosol radiative effects and climate predictability via driving larger processes like general circulation, nucleation, and warm water precipitation.

\section{Conclusion}

The recirculation zone is comprised the negative recirculation which supports the downdraft activities and positive recirculation which supports the updraft activities within the lower atmospheric setting. The negative recirculation has no influence on the rainfall pattern of an area-as seen in Oshogbo-Osun. The positive recirculation has significant influence on the rainfall pattern of an areaas seen in Ikeja-Lagos. The maximum turbulence kinetic energy over the research area is about $261 \mathrm{~J} / \mathrm{Kg}$ and occurs between $1000 \mathrm{~m}$ to $1500 \mathrm{~m}$ altitude. This altitude shows the role of recirculation in cloud formation and rainfall. Hence, the meteorological data set for the six locations shows that Ondo and Ikeja-Lagos has the highest value of turbulence kinetic energy. Also, we discover that the turbulence kinetic energy of negative recirculation is low i.e. compared with the turbulence kinetic energy of positive influence. The rainfall pattern of 2001 seems to be uniquely uniform with a clear evidence of uniform recirculation activity throughout the six locations. It was shown that recirculation activity influences the nature of clouds. The glaring results are the increase in cloud droplet number concentrations and a decrease of droplet effective radii. This result is possible because nucleation scavenging triggers rainfall both at the long or short term as shown in the results. Also, from figure 7 and 8 , it is concluded that recirculation is a complex process which triggers a reordering of the mixing layer-a key factor for initiating the type of rainfall in this region. Hence, the adaptation of the model formed on micro-scale conditions showed tremendous success in the meso-scale frame because of its flexibility to accommodate modifications.

\section{Acknowledgement}

The author acknowledges the Nigeria Meteorological Agency, NASA and Covenant University for allowing us to use their data set.

\section{References}

Akinyemi M.L., Emetere M.E. and Akinwumi S.A. (2016), Dynamics of Wind Strength and Wind Direction on Air Pollution Dispersion, Asian Journal of Applied Sciences, 4(2), 422-429.

Alfano M.J., Biehl L., Ensign T., Landenberger R., O'Neill M., Somers-Austin C., Exploring Aerosol Optical Thickness Using MODIS Satellite Imagery in NEO, http://serc.carleton.edu/usingdata/datasheets/aerosoloptic althick.html , 2015.

Allen R.J. and Sherwood S.C. (2010), The aerosol-cloud semi-direct effect and land-sea temperature contrast in a GCM, Geophys Res Lett, 37, L07702.

Bott A. (1999), A numerical model of the cloud-topped planetary boundary-layer: chemistry in marine stratus and the effects on aerosol particles, Atmospheric Environment, 33(12), 1921-1936.

Diem J.E. (2013), Response to comments on "Influences of the Bermuda High and atmospheric moistening on changes in summer rainfall in the Atlanta, Georgia region, the United States", International Journal of Climatology, 33, 3086-3088.

Emetere M.E. and Akinyemi M.L. (2015b), First Kind Plume Analysis of Volcanic Blast: Application of an Indigenous Model; IEEE Proceedings 2015 International Conference on Space Science and Communication, 136-140, 2015d

Emetere M.E., Akinyemi M.L. and Akinojo O. (2015a), Parametric retrieval model for estimating aerosol size distribution via the AERONET, LAGOS station, Environmental Pollution, 207(C), 381-390.

Emetere M.E., Akinyemi M.L. and Akin-Ojo O. (2015b), Aerosol Optical Depth Trends over Different Regions of Nigeria: Thirteen years Analysis, Modern Applied Science, 9(9), 267-279. 
Emetere M.E., Akinyemi M.L. and Uno U.E. (2015c), Computational Analysis of Aerosol Dispersion Trends From Cement Factory; IEEE Proceedings 2015 International Conference on Space Science and Communication, 288-291.

lacobellis S.F. and Somerville R.C.J. (2006), Evaluating parameterizations of the autoconversion process using a single-column model and Atmospheric Radiation Measurement Program measurements, J. Geophys. Res., 111, D02203.

Kim H.G. and Patel V.C. (2000), Test of turbulence models for wind flow over terrain with separation and recirculation, BoundaryLayer Meteorology, 94, 5-21.

Lee D., Sud Y.C., Oreopoulos L., Kim K.M., Lau W.K. and Kang I.S. (2014), Modeling the influences of aerosols on pre-monsoon circulation and rainfall over Southeast Asia, Atmos. Chem. Phys., 14, 6853-6866.

Mao K.B., Ma Y., Xia L., Wendy Y. Chen, Shen X.Y., He T.J. and Xu, T.R. (2014), Global aerosol change in the last decade: An analysis based on MODIS data, Atmospheric Environment, 94, 680-686.

Nober F.J., Graf H.F. and Rosenfeld D. (2003), Sensitivity of the global circulation to the suppression of precipitation by anthropogenic aerosols, Global and Planetary Change, 37(1), 57-80.

Okpani P.E. (2009), Determination of Aerosol Mass Loading in Ilorin Using Remote Sensing Technique, The Pacific Journal of Science and Technology, 10(2), 5-13.

Rotstayn L.D. and Lohmann U. (2002), Tropical rainfall trends and the indirect aerosol effect, J Clim., 15(15), 2103-2116.

Sadek R., Soulhac L., Brocheton F. and Buisson E. (2011), Evaluation of wind field and dispersion models in complex terrain, $14^{\text {th }}$ HARMO conference, 1-23.

Sobel A. (2010), Climate science: Raised bar for rain, Nature Geoscience, 3, 821-822.

Voiland A., Aerosols: Tiny Particles, Big Impact: Feature Articles, http://earthobservatory.nasa.gov/Features/Aerosols/page5. php, 2010

Weber T. and Quaas J. (2012), Incorporating the subgrid-scale variability of clouds in the autoconversion parameterization using a PDF-scheme, J. Adv. Model. Earth Syst., 4, M11003.

Westervelt D.M., Pierce J.R. and Adams P.J. (2014), Analysis of feedbacks between nucleation rate, survival probability and cloud condensation nuclei formation, Atmos. Chem. Phys., 14, 5577-5597, doi:10.5194/acp-14-5577-2014. 